\title{
3-Dimensional Analysis of Layer Structured Samples with High Depth Resolution Using Picosecond Laser-Induced Breakdown Spectroscopy
}

\author{
Rongxing Yia,b, Dongye Zhao ${ }^{b^{*}}$, Jannis Oelmann ${ }^{b}$, Sebastijan Brezinsek ${ }^{b}$, Marcin Rasinskib, Matej \\ Mayer $^{\mathrm{c}}$, Chandra Prakash Dhard ${ }^{\mathrm{d}}$, Dirk Naujoks ${ }^{\mathrm{d}}$, Liwei Liu ${ }^{\mathrm{a}^{*}}$, Junle $\mathrm{Qu}^{\mathrm{a}}$ and the W7-X teame.

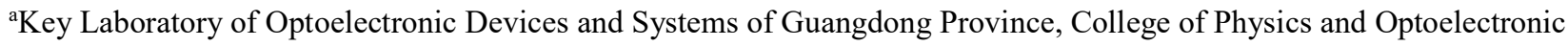 \\ Engineering, Shenzhen University, Shenzhen 518060, P. R. China. \\ ${ }^{b}$ Forschungszentrum Jülich, Institut für Energie- und Klimaforschung - Plasmaphysik, Partner of the Trilateral Euregio \\ Cluster (TEC), 52425 Jülich, Germany \\ ${ }^{\mathrm{c}}$ Max-Planck-Institut für Plasmaphysik, 85748 Garching, Germany \\ ${ }^{\mathrm{d}}$ Max-Planck-Institut für Plasmaphysik, 17491 Greifswald, Germany \\ 'The W7-X Team are the co-authors mentioned in the paper, T. Klinger et al., Nuclear Fusion 59 (2019) 112004
}

\begin{abstract}
Dimensional (3D) analysis is crucial for many materials and can be used to study their structure and properties. Laser-Induced Breakdown Spectroscopy (LIBS) is a versatile tool to get depth information quickly, but the poor depth resolution and in general a difficult quantification are the two main drawbacks. To solve these problems, a LIBS method based on picosecond-laser pulses is introduced. The ablation depth is measured and associated with the laser pulse number. A series of layer-structured graphite samples was tested by this method and the $2 \mathrm{D}$ and 3D layer structures of these samples were identified with a resolution of up to 24 and $102 \mathrm{~nm}$ for Mo and $\mathrm{C}$ elements under a residual pressure of $1 \times 10^{-5} \mathrm{~Pa}$, respectively. This shows the great potential of picosecond Laser-Induced Breakdown Spectroscopy (ps-LIBS) in the field of depth analysis.
\end{abstract}

\section{Introduction}

$3 \mathrm{D}$ information ( $\mathrm{x}, \mathrm{y}$ and depth directions) is of great interest for many materials. It can be used to investigate the structure of the materials, to study the relationship between the structure and the performance of the materials in the field of functional material, and to study the processes of plasmamaterial interactions in the field of laser processing and nuclear fusion $[1,2]$. Conventional methods which are used for obtaining the 2D or 3D elemental profile include: Scanning Electron Microscopy and Energy Dispersive X-ray spectroscopy (SEM/EDX), Scanning Electron Microscopy with Focused Ion Beam (SEM-FIB), Glow Discharge Optical Emission Spectrometry (GD-OES) and Elastic Backscattering Spectrometry (EBS). These methods are all classical methods and can be used to get useful information. However, SEM/EDX can't be applied to obtain depth information, SEM-FIB is powerful in depth analysis but time-consuming, GD-OES can provide high depth resolution but the lateral resolution is larger than $4 \mathrm{~mm}$, EBS performs excellent in depth and good in lateral resolution $(\sim 1 \mathrm{~mm})$ but the device is complicated and expensive. Above all, these methods have no or only small potential for in-situ analysis, which are their critical drawbacks.
Laser Induced Breakdown Spectroscopy (LIBS) is a spectrochemical analysis method based on analyzing spectra of a plasmas generated by material ablation induced by a pulsed laser. With its advantages of fast, in-situ analysis ability[3-5] and minimal sample preparation[6, 7], LIBS shows great potential in the fields of depth resolved analysis and remote monitoring. Though it is not a non-destructive method, the impact on the sample integrity is moderate with typical laser-induced craters of $1 \mathrm{~mm}$ in diameter or below.

In general, nanosecond-LIBS (ns-LIBS) is an established technology. The distribution of Li in lithium-ion batteries [8], materials deposition and retention on the nuclear fusion wall $[9,10]$, contamination and coatings in nuclear steel $[11,12]$, chemical imaging of tablet coatings [13] were all studied by using ns-LIBS. The obtained ablation rates of these studies ranged from 1-100 $\mu \mathrm{m}$. The heat diffusion and stress damage are very common in ns laser ablation due to its longer pulse width[14], which makes the identification of the actual interaction zone in the sample more complex in comparison to ultrashort laser pulses. Therefore, femtosecond (fs) laser is introduced to replace ns laser to avoid the thermal effect caused by the long laser pulse duration. Three-dimensional elemental imaging of Li-ion solid-state electrolytes [15] was 
performed by fs-LIBS. $\mathrm{Cr}, \mathrm{Si}, \mathrm{Cu}[16,17]$ and $\mathrm{Cu} / \mathrm{Ag}$ [18] materials were studied by fs laser, the best depth resolution reached $15 \mathrm{~nm}$ for $\mathrm{Cu} / \mathrm{Ag}$ material with a very weak spectral signal. These results confirmed a better depth resolution ability of fs-LIBS. However, in nuclear fusion, not only the metal materials should be taken into consideration, but also the penetrated $\mathrm{H} / \mathrm{He}$ needs to be measured[19], the ultrashort pulse duration and relatively lower energy of fs laser makes it challenging to measure trace $\mathrm{H} / \mathrm{He}$ in solid material. Meanwhile, in-situ LIBS systems on a remote handle arm in fusion devices are foreseen, which means compact solutions are required in the future for in-situ hydrogen retention measurements.

Therefore, a picosecond-LIBS (ps-LIBS) is introduced to do the depth analysis. Compared with fs-LIBS, materials can be ablated without thermal effects by ps-LIBS as well[20, 21], while a higher laser energy can be used to achieve stronger spectral intensity.

In this work, a method based on ps-LIBS is introduced and applied to measure the depth information of a series of layer structured samples from Wendelstein 7-X [22], W7-X, one of the largest stellarators in the world, which is used for studying magnetically confined plasmas. 3D elemental profiles of layer structured samples and their quantitative depth information were achieved under high vacuum conditions.

\section{Experimental setup and sample}

\subsection{Experimental setup}

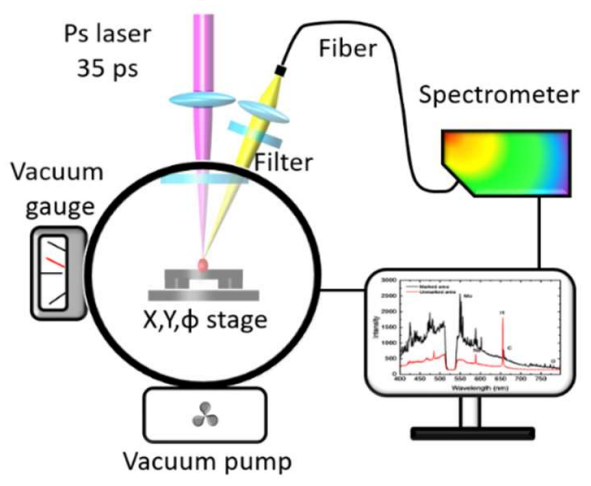

Figure 1. Ps-LIBS experimental setup.

The LIBS experimental apparatus used in this study are schematically shown in figure 1. A picosecond laser (EKSPLA, PL2241, wavelength: $355 \mathrm{~nm}$, repetition rate: $10 \mathrm{~Hz}$, pulse width: $35 \mathrm{ps)}$ was focused on the sample surface by a lens with a focal length of $500 \mathrm{~mm}$. By focusing the laser beam $2 \mathrm{~mm}$ below the sample surface, a diameter of $1 \mathrm{~mm}$ with a laser energy of $18 \mathrm{~mJ}$, a laser energy density of $2.4 \mathrm{~J} \mathrm{~cm}^{-2}$ was achieved. The samples were mounted onto a motorized XY $\backslash \Phi$ translation stage. A vacuum chamber and a set of vacuum pumps were used to create a residual pressure of $1 \times 10^{-5} \mathrm{~Pa}$ to simulate the pressures in the $\mathrm{W} 7-\mathrm{X}$ plasma vessel. The plasma emission was coupled into an optical fiber by an optical lens and then collected by a USB spectrometer (Ocean Optics,
HR2000, wavelength range: $350-800 \mathrm{~nm}$, ungated). Meanwhile, a laser notch filter (wavelength range: $345-365 \mathrm{~nm}$ and 515-535 $\mathrm{nm}$ ) was used to block the scattered laser light.

\subsection{Samples}

In Figure 2 (a), the locations of the 2 target modules (TM) with marker layer stripes are shown from which the analyzed samples were retrieved. These tiles were exposed to $\mathrm{H} / \mathrm{He}$ plasmas and retrieved at the end of the first operational phase in $\mathrm{W} 7-\mathrm{X}$ in divertor configuration. The technical names of the W7-X samples are very complex and will bring some confusions. Therefore, the measured samples have been simplified as A1-A5 and B1-B5 in this work, as shown in table 1. Samples A1-A5 and B1-B5 are taken from tile TM1v5 (target modules in vertical direction group 1 No. 5) and tile TM2v2 (target modules in vertical direction group 2 No. 2), respectively. The TM1v5 and TM2v2 were two normal tiles, which were placed at different locations in the W7-X.

Table 1. Nomenclature of samples

\begin{tabular}{c|c|c|c|c|c}
\hline Tile & \multicolumn{5}{|c}{ Sample number } \\
\hline $\mathrm{A}$ & 1 & 2 & 3 & 4 & 5 \\
\hline $\begin{array}{c}\text { W7-X name } \\
(\text { TM1v5 })\end{array}$ & $\mathrm{a} 503$ & 185 & 186 & 187 & $\mathrm{e} 503$ \\
\hline $\mathrm{B}$ & 1 & 2 & 3 & 4 & 5 \\
\hline $\begin{array}{c}\text { W7-X name } \\
\text { (TM2v2 })\end{array}$ & $\mathrm{a} 603$ & 191 & 192 & 193 & $\mathrm{e} 603$ \\
\hline
\end{tabular}

(a)

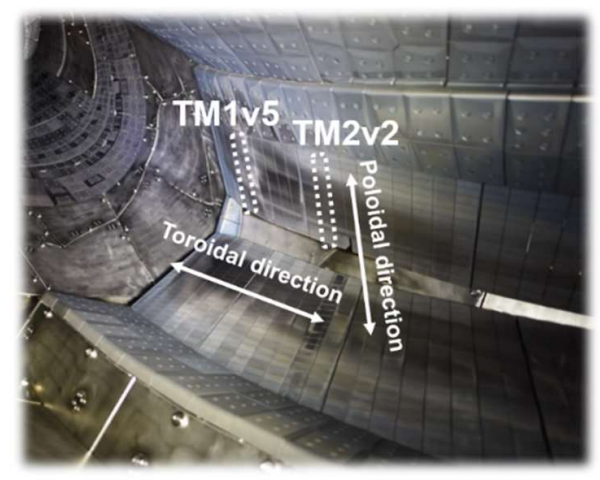

(b)

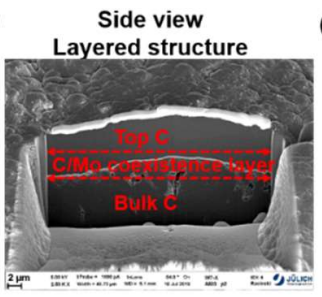

(c)

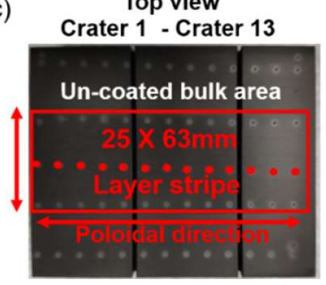

Figure 2. Sample measured by LIBS, (a) location of the samples, (b) layered structure of the sample, the top C layer is 5-10 $\mu \mathrm{m}$, the $\mathrm{C} /$ Mo coexistence layer is about $3.2 \mu \mathrm{m}$ (c) image of one sample and the laser craters.

Figure 2 (b) shows the layer structure of the samples, the thickness of the top $\mathrm{C}$ layer ranges from 5-10 $\mu \mathrm{m}$, the thickness of the thin pure Mo layer is around $200 \mathrm{~nm}$. However, the profile of Mo layer is not a straight line, the 
thickness of the C/Mo coexistence layer is about $3.2 \mu \mathrm{m}$ (distance between the two red dashed lines) in depth direction in this crater. After interaction with plasma in W7$\mathrm{X}$, erosions or depositions occurred in these samples. To study the erosions or depositions, 3-dimensional elemental information is very helpful, especially along the depth. As shown in Figure 2 (c), the sample with the marker layer stripe (stripe area $63 \times 25 \mathrm{~mm}$ ) was measured by LIBS with a crater of $1 \mathrm{~mm}$ on the sample. The distance between two craters was $5 \mathrm{~mm}$. Measurements were done along the five lines, three on the marker layer stripe and two on the sides, each line contained 13-15 laser craters. In order to achieve depth resolved information about the material composition, 200 laser pulses were used for the subsequent ablation to ablate the whole marker layer and spectra recorded of every single ablation. Sample A1-A5 and B1-B5 were analyzed by this method. After the LIBS analysis, small craters (diameter of around $1 \mathrm{~mm}$ ) will remain in the sample surface with a depth of about $8 \mu \mathrm{m}$ (measured by mechanical profilometry, Dektak 6M). This depth is comparable to the sample surface roughness, which means they will barely impact on the plasma-facing components properties.

\section{RESULTS AND DISCUSSION}

\subsection{Qualitative judgement of depth information}

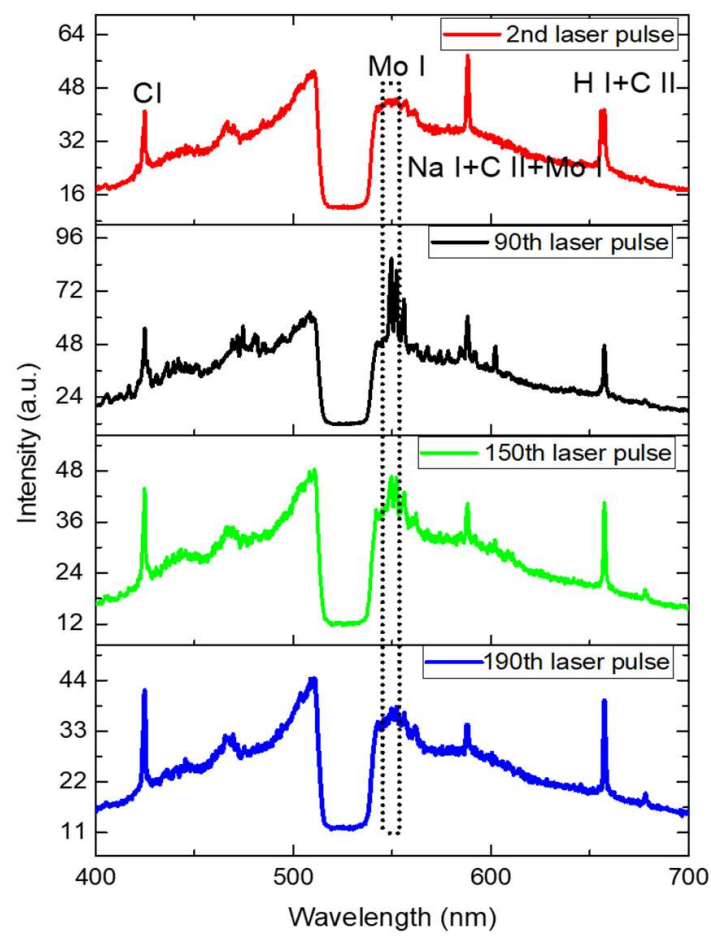

Figure 3. Typical spectra from one sample of the layered structure for different pulse number with Mo layer in marker area. The peaks of $\mathrm{Mo}, \mathrm{Na}, \mathrm{H}$ and $\mathrm{C}$ elements are observed. Due to a laser notch filter (532 nm laser filter), a dip appeared in the region from 515$535 \mathrm{~nm}$.
LIBS spectra of different laser pulses in the marker area are shown for a sample in figure 3. The signals of $\mathrm{Mo}, \mathrm{Na}$, $\mathrm{H}$ and $\mathrm{C}$ elements can be observed clearly. Obviously, the spectral intensities varied from pulse to pulse, especially for the Mo I line at $550.65 \mathrm{~nm}$ (marked by black dots box). In the spectrum of the $2^{\text {nd }}$ laser pulse, Mo was not detectable in general due to the existence of the top C layer. After the graphite was ablated clearly by tens of laser pulses, the Mo signal appeared, as shown in the spectra of the $90^{\text {th }}$ and $150^{\text {th }}$ laser pulse. When the $\mathrm{C} / \mathrm{Mo}$ coexistence layer was completely ablated, the Mo signal disappeared again, as shown in the last spectrum.
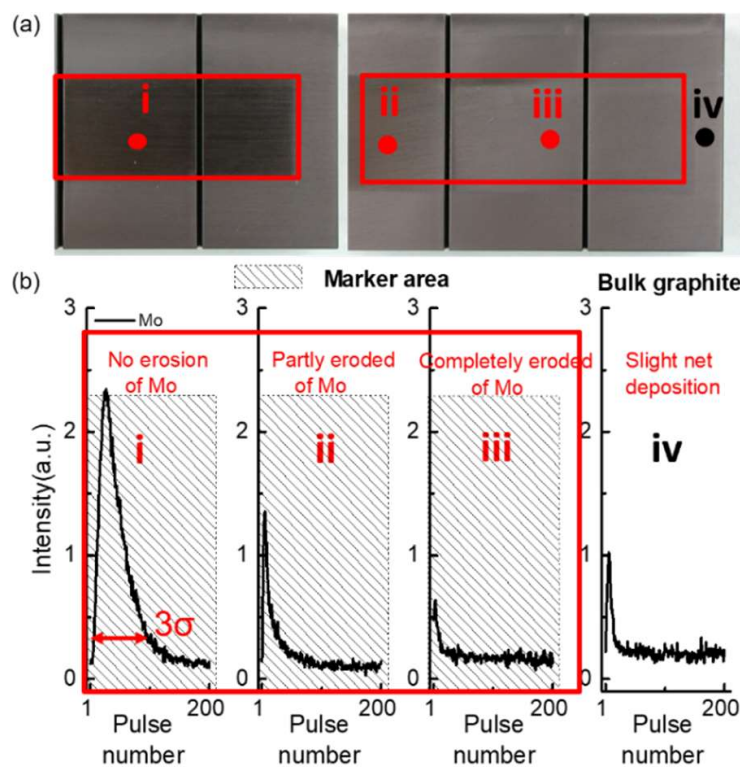

Figure 4. (a) The position of different craters and (b) corresponding intensities of Mo. For a judgement of erosion and deposition, the

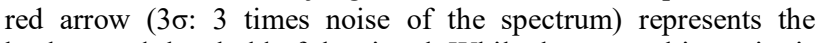
background threshold of the signal. While the spectral intensity is higher than the line, it is considered as an effective signal. Position iv is outside of the initially coated area.

The variation of the spectral intensity of different laser pulses on a sample can provide useful depth resolved composition information. To get the depth resolved composition information in the present study, the relationship between pulse number and Mo spectral intensity is analysed in different samples. Figure 4 shows the Mo spectral intensity (Mo I at $550.65 \mathrm{~nm}$ ) distribution in depth direction (different laser pulses), the data of 4 typical positions along the poloidal directions on the samples are presented. As shown in the upper part of figure 4 (a), position i represents the area without erosion of Mo (the top C layer was partly eroded), position ii represents the area with nearly half erosion of Mo, position iii represents the area where Mo was almost completely eroded and position iv represents the area without marker layer initially. The relationship between pulse number and Mo spectral intensity is shown in figure 4 (b). In position i, the Mo signal is observed for more than 90 laser pulses, the rising and falling 
of the Mo spectral intensity can be observed clearly, which meant there was an intact Mo layer with the $\mathrm{C}$ layer above. In position ii, the Mo signal was observed for about 30 laser pulses and the rising of the Mo spectral intensity disappeared, which indicated the $\mathrm{C} / \mathrm{Mo}$ coexistence layer was partly eroded. In position iii, the Mo signal was observed for less than 10 laser pulses, which represented that almost the entire Mo layer was eroded. Finally, in position iv, the Mo signal was observed for several laser pulses, which meant a slight deposition of Mo occurred due to transport of eroded atoms.

Moreover, the depth of the Mo layer can be calculated qualitatively by the number of pulses during appearance and disappearance of the effective Mo I signal (The LIBS signal is taken as effective signal, while the spectral intensity is higher than $3 \sigma$ of the spectrum, $\sigma$ is the spectral noise.). As shown in figure 4, data above the red arrow were regarded as the effective signal and the width of the peak correlated with the number pulses during the effective signal. The beginning and ending of effective signal represented the upper and lower surface of the C/Mo coexistence layer.
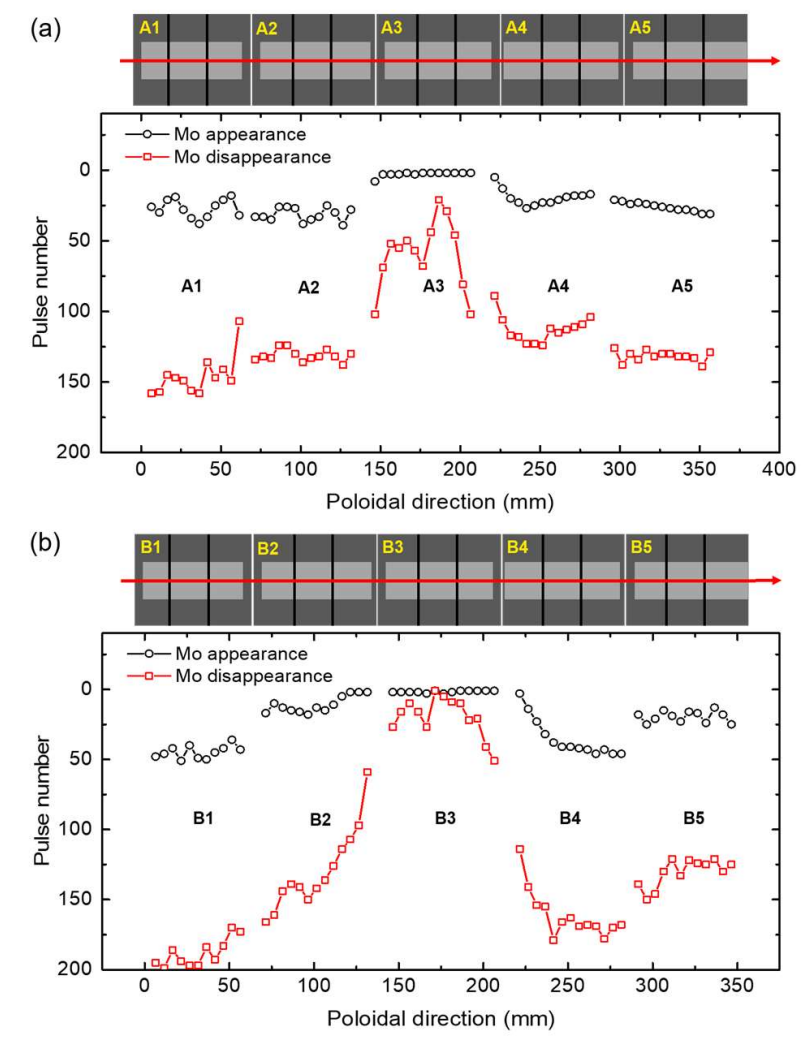

Figure 5. The Mo signal appearance (black hollow points) and disappearance laser pulse numbers (red hollow points) for different ablated craters on the series samples of (a) Tile A $(1,2,3,4,5)$ and (b) Tile B $(1,2,3,4,5)$, respectively. (The data come from the middle row in figure $2(\mathrm{c})$ )

According to the measurement principle of effective signal and the relationship between pulse number and Mo spectral intensity, the beginning and ending of the effective signal of every laser crater on the marker layer was obtained. Figures 5 (a) and (b) show the appearance (black hollow points) and disappearance laser pulse numbers (red hollow points) of all the ablated craters in divertors from Tile $\mathrm{A}$ and Tile B, respectively. There was no signal of Mo before the laser pulse number of the black hollow point and after that of the red hollow point, which means no Mo element existed in the layer ablated by these laser pulses. Therefore, the thickness of the top C layer is related to the pulse number of the black hollow point, while the thickness of the $\mathrm{C} / \mathrm{Mo}$ coexistence layer is related to the number of pulses between the black hollow point and the red hollow point.

As shown in figure 5, the thickness of the top C layer changed with the position on the sample. For the series samples of Tile A, compared to the areas in the middle, there was less erosion at both ends. On the left side, the thickness of the top C layer corresponded to about 20-40 "laser pulses" and the thickness of the $\mathrm{C} / \mathrm{Mo}$ coexistence layer corresponded to about 100-130 "laser pulses" in these positions. However, erosion became more serious in the center of Tile A, the top C layer was practically eroded and the thinnest depth of the $\mathrm{C} / \mathrm{Mo}$ coexistence layer corresponded to 24 "laser pulses". Compared with Tile A, erosion of Tile B was much more serious in the center area, not only the top $\mathrm{C}$ layer but also the $\mathrm{C} / \mathrm{Mo}$ coexistence layer were entirely eroded in these positions, no Mo signal can be obtained even in the first few laser pulses.

\subsection{Quantitative judgement of depth resolved information}

The above results showed the depth resolved information of Mo and C qualitatively, to obtain quantitative depth resolved information of the layers, ablation rates due to the same number of laser pulses for different elements were studied. Figure 6 (a) shows profiles of laser craters (60 pulses) of pure graphite part (W7-X divertor), which was obtained by profilometer, the roughness $(\mathrm{Rq}$, root mean square deviation, about $2.1 \mu \mathrm{m}$ ) of the surface can be observed clearly. The ablation rate can be calculated by the laser pulse number and the ablation depth. Due to the shallow depth and relatively wide crater diameter [23], the ablation rate will be stable in our measurement (crater depth around $8 \mu \mathrm{m}$ and crater diameter around $1000 \mu \mathrm{m})$.

Ablation rates of 4 different materials (polished Mo, W, $\mathrm{Cu}$, and fine grain graphite, all of them are bulk material with polished surfaces, roughness $\mathrm{R}_{\mathrm{q}}$ around $100 \mathrm{~nm}$ ) are obtained by this method (100 pulses for each) are shown in table 2 . The relationships between the calculated ablation rate of 4 materials and their laser fluences were analyzed, as shown in Figure 6 (b). The data matched well with log fit (when fluence is $<2.5 \mathrm{~J} / \mathrm{cm}^{2}$ except $\mathrm{Cu}$ for which it is $<2 \mathrm{~J} / \mathrm{cm}^{2}$. In the equation, $\mathrm{L}$ represents ablation rate, $\alpha^{-1}$ is the optical penetration depth, $F_{\text {th }}$ is the ablation threshold fluence and $F$ is the real ablation fluence), expected from ablation rate theory [24]. The different absorption efficiency, optical 
penetration depth [25] and boiling point lead to the distinctive ablation rate among these materials. The results show that the ablation rates of Mo and $\mathrm{W}$ were both lower than $40 \mathrm{~nm} /$ pulse under our experimental parameters. The ablation rate of graphite was a little higher, $102 \mathrm{~nm} / \mathrm{pulse}$. The ablation rate determines the depth resolution of our method, which indicated a best resolution of $24 \mathrm{~nm}$ for Mo element (laser fluence: $2.3 \mathrm{~J} / \mathrm{cm}^{2}$ ). The depth resolution of the applied ps-LIBS setup is comparable to some typical results of fs-LIBS, such as $40 \mathrm{~nm}$ for $\mathrm{Si}$ [26] with a fluence of $1.4 \mathrm{~J} / \mathrm{cm}^{2}$ and $55 \mathrm{~nm}$ for $\mathrm{Cr}$ [16] with a fluence of $1.8 \mathrm{~J} / \mathrm{cm}^{2}$, which proves its excellent depth resolution ability. Furthermore, the same laser is applied to measure Hydrogen (gas retention, low concentration) in the divertor as well, which is a challenge for fs laser.
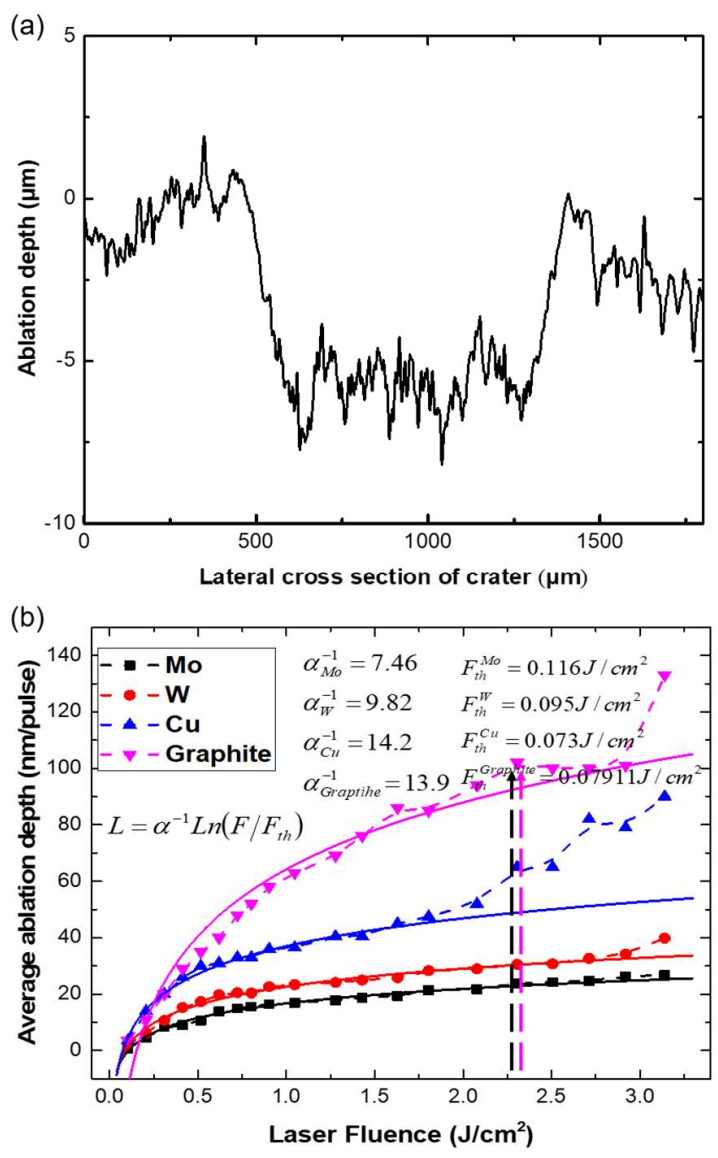

Figure 6. Profilometer measurement and analysis of the ablation depth for different laser fluences and materials. (a) Ablation profile of graphite sample obtained by profilometer. (b) Relationship between average ablation depth and laser fluence of different materials (relative error $<10 \%$ ).

Table 2. Ablation rate of different materials (Laser fluence: $2.3 \mathrm{~J} / \mathrm{cm}^{2}$ )

\begin{tabular}{c|c|c|c|c}
\hline Material & Mo & $\mathrm{W}$ & $\mathrm{Cu}$ & $\mathrm{C}$ \\
\hline $\begin{array}{c}\text { Ablation rate } \\
\text { (nm/pulse) }\end{array}$ & 24 & 30 & 64 & 102 \\
\hline
\end{tabular}

By combining the ablation rate with the qualitative depth information (pulse number data in figure 5), quantitative depth of the marker area was obtained. Visualizations of the depth information of the top $\mathrm{C}$ layer and the $\mathrm{C} / \mathrm{Mo}$ coexistence layer on Tile A and Tile B samples in poloidal direction are shown in figure 7. The gray area represents the thickness of the top $\mathrm{C}$ layer and the red area represents the thickness of the C/Mo coexistence layer (it should be clarified that the thickness of the C/Mo coexistence layer represents the distribution of Mo in depth direction. The depth which contains Mo is thicker than $3 \mu \mathrm{m}$, although the thickness of the pure Mo layer is only $200 \mathrm{~nm}$, as shown in fig. 2(b)). These results consequently contained information in poloidal and depth direction, which makes this method a 2D analysis. Similar erosion results of graphite and Mo were obtained in the EBS results, both the results showed that the erosion dominated area locates in the B3 sample [27].
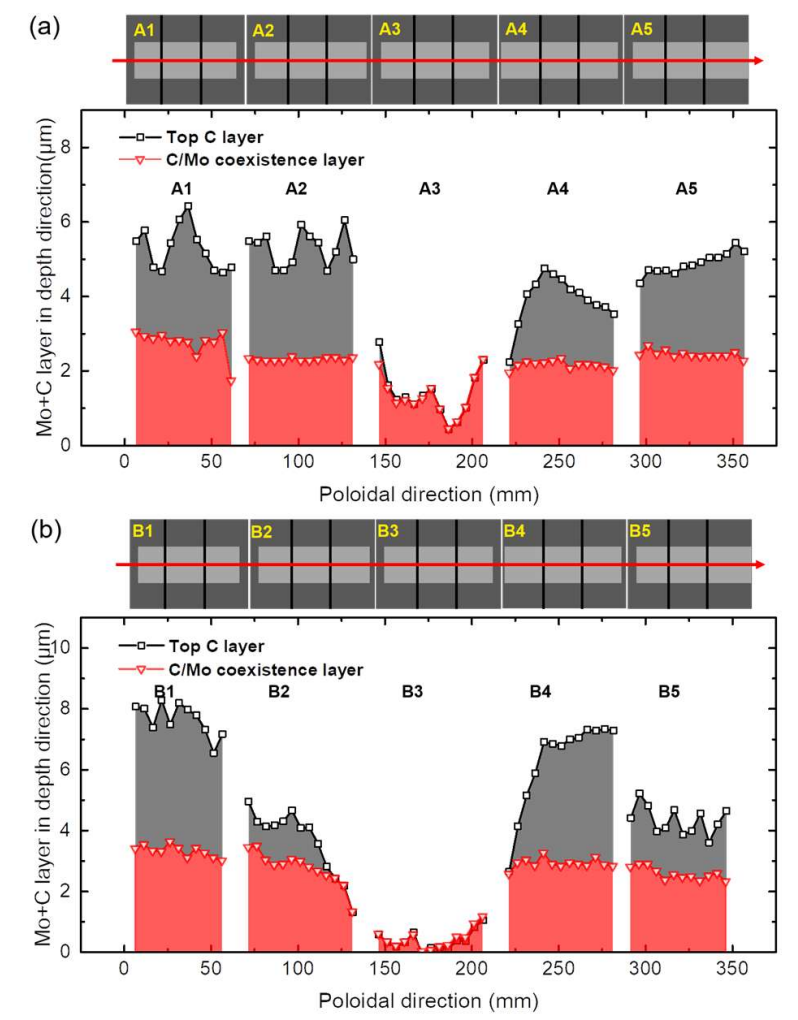

Figure 7. Quantitative depth information of marker area in poloidal direction of (a) Tile A (1, 2, 3, 4, 5) and (b) Tile B (1, 2, 3, 4, 5), respectively. The gray and the red area represent the approximate top C layer and the C/Mo coexistence layer, respectively.

Figure 8 shows depth information in poloidal and toroidal direction, which makes this method a 3D analysis. The selected sample was sample A3, which was eroded seriously in tile A. The marker area was about $63 \times 25 \mathrm{~mm}^{2}$, which contains $13 \times 5=65$ craters. The depth of surrounding area was set as zero in fig. 8 as there was no marker layer. In sample A3, erosion of Mo almost appeared everywhere, only on the edge of the sample, some thin graphite layers remained. 


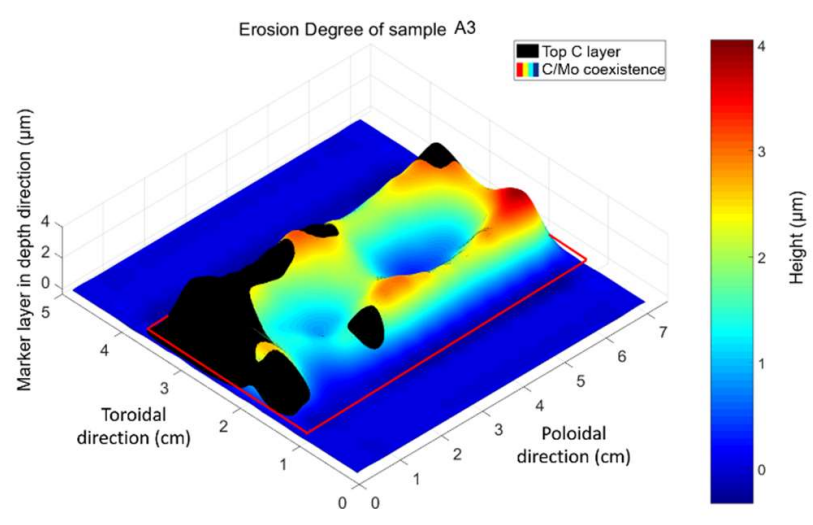

Figure 8. 3D elemental profile of sample A3 with a depth resolution of $24 \mathrm{~nm}$. The marker area is marked by a red line. The black layer represents the remaining graphite layer.

\subsection{Verification of the results of LIBS}

Scanning Electron Microscope (SEM) and Energy Dispersive X-ray spectroscopy (EDX) were used to exam the results of LIBS. 8 points were ablated by different laser pulses in sample B1 (this sample was less eroded). As shown in Figure 9 (a), there was no distinct Mo signal in the first 40 laser pulses (very weak signal around 40 pulses), after 58 pulses the Mo signal started to increase rapidly and reached its maximal value around 90 pulses. Then the Mo signal decreased gradually until 190 pulses. These 4 typical points were verified by SEM and EDX. The electron beam penetration depth of EDX analysis at $5 \mathrm{keV}$ is less than 0.3 $\mu \mathrm{m}$, which indicates a $0.3 \mu \mathrm{m}$ offset for EDX results. As shown in Figure 9 (b), no distinct Mo signal (EDX concentration $0.3 \%$ ) was detected within $0.3 \mu \mathrm{m}$ below the craters produced after 40 and 190 laser pulses, while an obvious Mo signal can be detected within $0.3 \mu \mathrm{m}$ below the craters of 58 laser pulses, and a significant Mo signal appeared within $0.3 \mu \mathrm{m}$ below the crater produced after 90 laser pulses. The LIBS results and EDX results exhibited the same tendency of change in Mo signal. Given the $2.1 \mu \mathrm{m}$ roughness of the crater surface, the $0.3 \mu \mathrm{m}$ offset did not influence the agreement between LIBS and SEM-EDX results.

The depth resolution ability of LIBS has been verified in this work, its advantages of rapid and large area detection makes it more convenient when compared with FIB-SEM and EBS. Moreover, all the results were obtained under residual pressure of $1 \times 10^{-5} \mathrm{~Pa}$ (used to simulate the pressures in $\mathrm{W} 7-\mathrm{X})$, which shows its potential application of in-situ analysis in W7-X. However, the low pressure is not indispensable, this method can be used in a normal ambient pressure as well, and a simpler setup can be obtained when the vacuum system is removed. The depth resolution is better than $100 \mathrm{~nm}$ for many elements, but the roughness of the sample influenced the depth resolution. To reduce this influence, a better lateral resolution is necessary. Therefore, to improve the performance of lateral resolution while maintaining the advantage of depth resolution is the key challenge of future work.

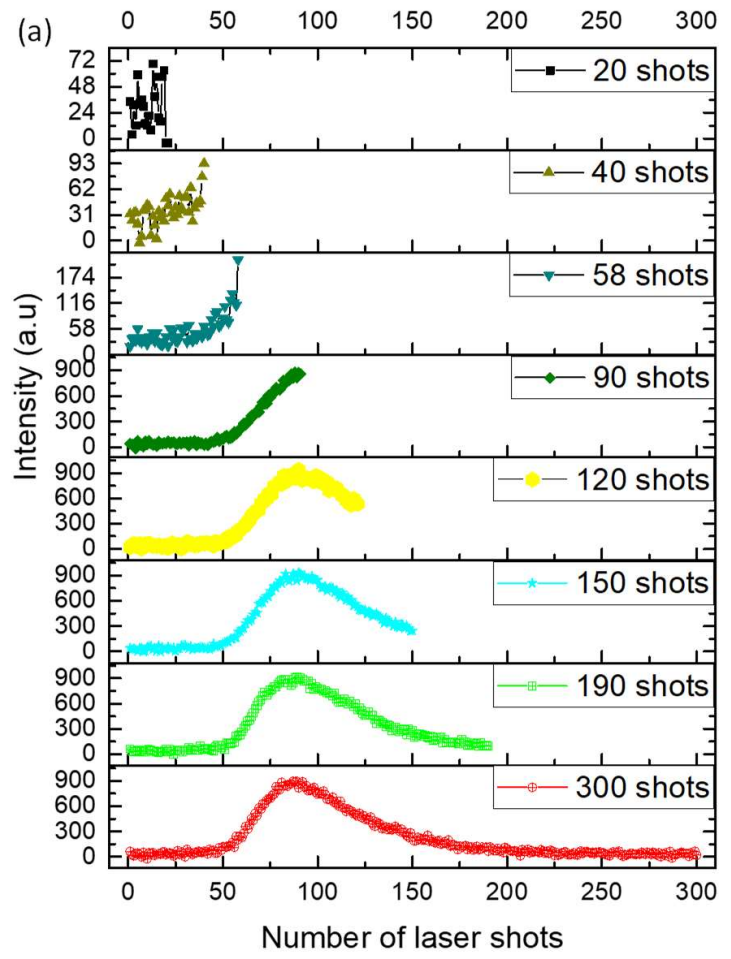

(b)

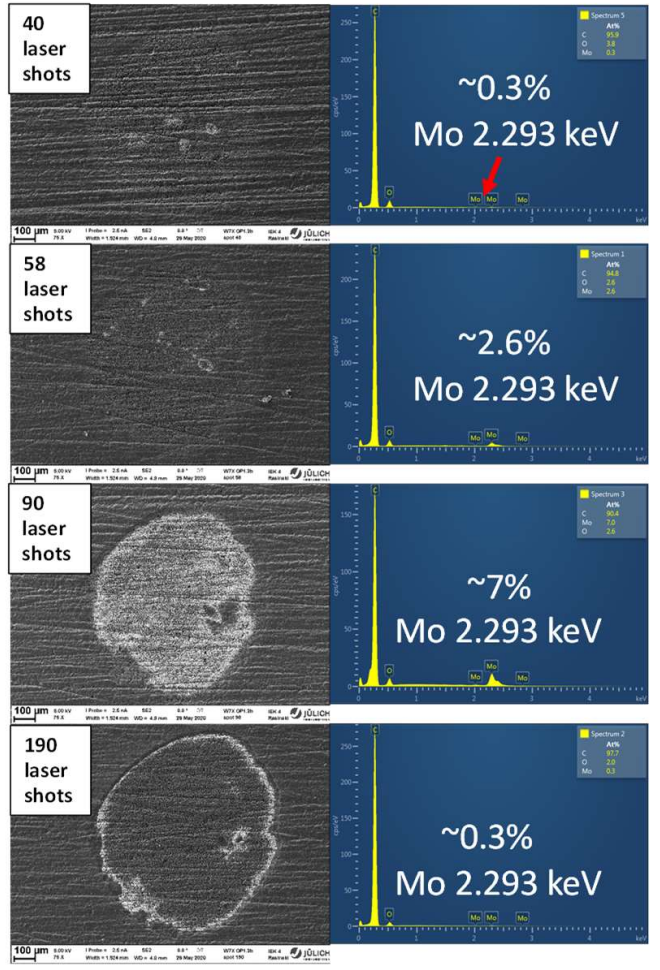

Figure 9. (a) Signal of Mo under different laser pulses, (b) SEM images and EDX results of corresponding specific laser pulses.

\section{CONCLUSIONS}

In this work, an analytical method based on ps-LIBS was proposed to $3 \mathrm{D}$ analysis of $\mathrm{C} / \mathrm{Mo}$ layer structured samples 
with high depth resolution. Using this method, the $\mathrm{C} / \mathrm{Mo}$ spectral intensities of different laser pulses were measured and applied to determine the depth of the layer structured samples. The analyzed area was larger than $63 \times 25 \mathrm{~mm}^{2}$ and the analyzed layer structured sample thickness was higher than $8 \mu \mathrm{m}$. Furthermore, the best depth resolutions of this method were 24 and $102 \mathrm{~nm}$ for Mo and C elements, respectively. It is believed that, with the improvement of the laser crater lateral resolution, the ps-LIBS method is promising for future in-situ high resolution 3D elemental profile analysis.

\section{AUTHOR INFORMATION}

\section{Corresponding Author}

E-mail: do.zhao@fz-juelich.de,liulw@szu.edu.cn

\section{Notes}

The authors declare no competing financial interest.

\section{Author Contributions}

The manuscript was written through contributions of all authors. All authors have given approval to the final version of the manuscript.

\section{ACKNOWLEDGMENT}

This work has been carried out within the framework of the EUROfusion Consortium and has received funding from the Euratom research and training programme 2014-2018 and 2019-2020 under grant agreement No 633053. The views and opinions expressed herein do not necessarily reflect those of the European Commission. This project is supported by The National Key Research and Development Program of China (2017YFA0700402). The National Natural Science Foundation of China (11904241/11905049/61722508/ 61525503/61620106016/ 81727804). Guangdong Natural Science Foundation Innovation Team (2014A030312008), and Shenzhen Basic Research Project (JCYJ20150930104948169/ JCYJ20160328144746940/ GJHZ20160226202139185/ＪCYJ20170412105003520). China Postdoctoral Science Foundation funded project 2018M643159. Project of Science and Technology Department of Sichuan Province (No. 2020YJ0181) and the Joint Sino-German Research Project (NSFC-DFG)

\section{REFERENCES}

[1] J. Beuth, J. Fox, J. Gockel, C. Montgomery, R. Yang, H. Qiao, E. Soylemez, P. Reeseewatt, A. Anvari, S. Narra, Process mapping for qualification across multiple direct metal additive manufacturing processes, in: Proceedings of SFF Symposium., Austin, TX, Aug, 2013, pp. 12-14. [2] R. Montanari, B. Riccardi, R. Volterri, L. Bertamini, Characterisation of plasma sprayed $\mathrm{W}$ coatings on a $\mathrm{CuCrZr}$ alloy for nuclear fusion reactor applications, Materials Letters, 52 (2002) 100-105.

[3] M.Z. Martin, S. Allman, D.J. Brice, R.C. Martin, N.O. Andre, Exploring laser-induced breakdown spectroscopy for nuclear materials analysis and in-situ applications, Spectrochimica Acta Part B: Atomic Spectroscopy, 74 (2012) 177-183.
[4] V. Philipps, A. Malaquias, A. Hakola, J. Karhunen, G. Maddaluno, S. Almaviva, L. Caneve, F. Colao, E. Fortuna, P. Gasior, Development of laser-based techniques for in situ characterization of the first wall in ITER and future fusion devices, Nuclear fusion, 53 (2013) 093002.

[5] A. Huber, B. Schweer, V. Philipps, R. Leyte-Gonzales, N. Gierse, M. Zlobinski, S. Brezinsek, V. Kotov, P. Mertens, U. Samm, Study of the feasibility of applying laser-induced breakdown spectroscopy for in-situ characterization of deposited layers in fusion devices, Physica scripta, 2011 (2011) 014028.

[6] J.D. Winefordner, I.B. Gornushkin, T. Correll, E. Gibb, B.W. Smith, Comparing several atomic spectrometric methods to the super stars: special emphasis on laser induced breakdown spectrometry, LIBS, a future super star, Journal of Analytical Atomic Spectrometry, 19 (2004) 1061-1083. [7] Z. Wang, T.-B. Yuan, Z.-Y. Hou, W.-D. Zhou, J.-D. Lu, H.-B. Ding, X.-Y. Zeng, Laser-induced breakdown spectroscopy in China, Frontiers of Physics, 9 (2014) 419-438.

[8] S. Imashuku, H. Taguchi, S. Fujieda, S. Suzuki, K. Wagatsuma, Threedimensional lithium mapping of graphite anode using laser-induced breakdown spectroscopy, Electrochimica Acta, 293 (2019) 78-83.

[9] R. Hai, P. Liu, D. Wu, Q. Xiao, L. Sun, H. Ding, Effect of steady magnetic field on laser-induced breakdown spectroscopic characterization of EAST-like wall materials, Journal of Nuclear Materials, 463 (2015) 927930.

[10] G. Shaw, M. Bannister, T.M. Biewer, M.Z. Martin, F. Meyer, B.D. Wirth, The detection of He in tungsten following ion implantation by laserinduced breakdown spectroscopy, Applied Surface Science, 427 (2018) 695-703.

[11] Y. Li, C. Ke, X. Liu, F. Gou, X. Duan, Y. Zhao, Analysis liquid lithium corrosion resistance of Er2O3 coating revealed by LIBS technique, Fusion Engineering and Design, 136 (2018) 1640-1646.

[12] A. Lang, D. Engelberg, N.T. Smith, D. Trivedi, O. Horsfall, A Banford, P.A. Martin, P. Coffey, W.R. Bower, C. Walther, Analysis of contaminated nuclear plant steel by laser-induced breakdown spectroscopy, Journal of hazardous materials, 345 (2018) 114-122.

[13] L. Zou, B. Kassim, J.P. Smith, J.D. Ormes, Y. Liu, Q. Tu, X. Bu, In situ analytical characterization and chemical imaging of tablet coatings using laser induced breakdown spectroscopy (LIBS), Analyst, 143 (2018) 5000-5007.

[14] K.L. Eland, D.N. Stratis, T. Lai, M.A. Berg, S.R. Goode, S.M. Angel, Some comparisons of LIBS measurements using nanosecond and picosecond laser pulses, Applied Spectroscopy, 55 (2001) 279-285.

[15] H. Hou, L. Cheng, T. Richardson, G. Chen, M. Doeff, R. Zheng, R. Russo, V. Zorba, Three-dimensional elemental imaging of Li-ion solid-state electrolytes using fs-laser induced breakdown spectroscopy (LIBS), Journal of Analytical Atomic Spectrometry, 30 (2015) 2295-2302.

[16] S. Banerjee, R. Fedosejevs, Single shot depth sensitivity using femtosecond laser induced breakdown spectroscopy, Spectrochimica Acta Part B: Atomic Spectroscopy, 92 (2014) 34-41.

[17] S. Banerjee, T. Sarnet, P. Siozos, M. Loulakis, D. Anglos, M. Sentis, Characterization of organic photovoltaic devices using femtosecond laser induced breakdown spectroscopy, Applied Surface Science, 418 (2017) $542-547$

[18] V. Margetic, M. Bolshov, A. Stockhaus, K. Niemax, R. Hergenröder, Depth profiling of multi-layer samples using femtosecond laser ablation, Journal of Analytical Atomic Spectrometry, 16 (2001) 616-621.

[19] J. Oelmann, N. Gierse, C. Li, S. Brezinsek, M. Zlobinski, B. Turan, S Haas, C. Linsmeier, Depth-resolved sample composition analysis using laser-induced ablation-quadrupole mass spectrometry and laser-induced breakdown spectroscopy, Spectrochimica Acta Part B: Atomic Spectroscopy, 144 (2018) 38-45.

[20] D. Zhao, N. Gierse, J. Oelmann, S. Brezinsek, M. Rasinski, Y. Liang, C. Linsmeier, H. Ding, Investigation of laser ablation features of molybdenum bulk for picosecond laser-based techniques in fusion devices, Fusion Engineering and Design, 151 (2020) 111379.

[21] I.A.e. Artyukov, D. Zayarniy, A.A. Ionin, S.I. Kudryashov, S.V. Makarov, P.N. Saltuganov, Relaxation phenomena in electronic and lattice subsystems on iron surface during its ablation by ultrashort laser pulses, JETP letters, 99 (2014) 51-55.

[22] V. Winters, S. Brezinsek, F. Effenberg, M. Rasinski, O. Schmitz, L. Stephey, C. Biedermann, C. Dhard, H. Frerichs, J. Harris, Overview of the plasma-surface interaction on limiter surfaces in the startup campaign of Wendelstein 7-X, Physica Scripta, 2017 (2017) 014050.

[23] J. Zhang, Y. Chen, M. Hu, X. Chen, An improved three-dimensional two-temperature model for multi-pulse femtosecond laser ablation of aluminum, Journal of Applied Physics, 117 (2015) 063104.

[24] R. Le Harzic, D. Breitling, M. Weikert, S. Sommer, C. Föhl, S. Valette, C. Donnet, E. Audouard, F. Dausinger, Pulse width and energy influence 
on laser micromachining of metals in a range of $100 \mathrm{fs}$ to $5 \mathrm{ps}$, Applied Surface Science, 249 (2005) 322-331.

[25] S. Preuss, A. Demchuk, M. Stuke, Sub-picosecond UV laser ablation of metals, Applied physics A, 61 (1995) 33-37.
[26] S. Banerjee, Z. Chen, I. Utkin, R. Fedosejevs, Detection of buried layers in silicon devices using LIBS during hole drilling with femtosecond laser pulses, Applied Physics A, 111 (2013) 791-798.

[27] M. Mayer, M. Balden, S. Brezinsek, V. Burwitz, C. Dhard, A. Dudek, G. Ehrke, Y. Gao, H. Greuner, R. Guimarães, Material erosion and deposition on the divertor of W7-X, Physica Scripta, T171 (2020) 014035. 